\title{
REVIEW
}

\section{Current progress in chronohaematology}

\author{
Josef Berger \\ Faculty of Health and Social Studies, University of South Bohemia, České Budějovice, Czech Republic
}

Received $10^{\text {th }}$ May 2006.

Published online $21^{\text {st }}$ June 2006.

\begin{abstract}
Summary
Cyclic changes play an important part of the space structure of an organism. Knowledge of the rhythms in haematological characteristics is important for both laboratory medicine and comparative pathology. New findings in chronohaematology published during the last two years are discussed. It seems that the haemato-immune circadian system reflects a circadian clock which is partially independent on the circadian clock in suprachiasmatic nuclei.
\end{abstract}

Keywords: circadian - clock gene - leukocyte - melatonin - platelet - seasonal

\section{INTRODUCTION}

Time is measured in living systems by various rhythms. Cyclic fluctuations and developmental changes represent the time structure of organisms which is studied by many chronobiological and physiological disciplines, while the space structure is observed in cytology, histology, anatomy and related sciences. Regular changes in blood pictures during the day were among the first circadian rhythms documented, and the finding of rhythms in haematopoiesis indicate that the rhythms in circulating blood cells occur in haematopoietic organs (Berger 2004b, for review).

Melatonin, dubbed the hormone of darkness and known as an internal synchroniser of circadian oscillations in mammals, acts on blood and haema-

Josef Berger, Faculty of Health and Social Studies, University of South Bohemia, Branišovská 31, 37005 České Budějovice, Czech Republic 口 berger@jcu.cz topoietic cells as an immunostimulator and cytoprotective agent (Sánchez et al. 2004, Hardeland et al. 2006). Melatonin also influences neuronal firing in the suprachiasmatic nucleus via MT G protein-coupled receptors (Dubochovich and Markowska 2005). A relationship between clock genes and melatonin synthesis (Reppert and Weaver 2001, Berger 2004a) and melatonin receptors on leukocytes (Kwiatkowski and Lévi 2005) could support the hypothesis that melatonin generates circadian rhythms in haematopoiesis (Maestroni 1998).

There are many positive effects of sunlight on human health and the health of other organisms, including those produced via the synchronisation of biorhythms (Roberts 2005).

\section{CIRCADIAN RHYTHMS}

Several papers have documented over the last two years new characteristics in rhythms: the rhythmicity of some haematological parameters, the erythrocyte count, the total leukocyte count, the 
platelet count, the haematocrit, the haemoglobin level, the mean corpuscular volume, and the mean corpuscular haemoglobin and mean corpuscular haemoglobin concentration have been found in horses (Piccione et al. 2005a). Circadian rhythms in the prothrombin time of the athletic horse have nocturnal acrophase (Piccione et al. 2005b). Known circadian rhythms in phagocytic ingestion of neutrophils, neutrophil adherence and counts terminate after subacute ethanol administration and are restored following melatonin. It supports the hypothesis that pineal-hypothalamic pathways regulate phagocytosis (Hriscu 2005). On the other hand, iron deficiency suppresses circadian changes in monocyte phagocytosis (Barkova and Nazarenko 2005). A significant circadian fluctuation of glucose-6-phosphate dehydrogenase was found in both erythrocytes and neutrophils (Wolach et al. 2004).

The more frequent onset of acute coronary syndromes in the morning hours has been known for a long time. Manfredini and co-workers (2004) confirmed circadian variation peaked between 6 a.m. and noon and found a statistically notsignificant trend toward a higher frequency of fatal cases in this period. Several groups have shown a relationship between myocardial infarction and the timing of many physiological processes including haemocoagulation and fibrinolysis. The lesser activity of the tissue plasminogen activator, a key factor behind fibrinolytic activity, the greater activity of the plasminogen activator inhibitor-1 (PAI-1) in the morning. This results in circadian fluctuations of fibrinolysis, correspond with the timing of myocardial infarction. Hypercholesteronemia enhances the daily expression of PAI-1 gene (Kudo et al. 2004) and, therefore, may augment acute atherothrombotic events in the morning hours. Impairment of the coagulation and fibrinolytic systems induced by diabetes is partly due to impaired circadian PAI-1 changes at the level of mRNA transcription (Oishi et al. 2004). Exercise time can also influence platelet activation: morning exercise induces an increase in platelet counts while platelet aggregation measured following ADP addition, decreased (Aldemir and Kilic 2005). Plasma concentrations of soluble P-selectin are higher in the evening, this elevation can represent the shed forms of the morning membrane-bound $\mathrm{P}$ selectin in platelets (Osmacik et al. 2004).

The efficacy of thrombolytic drugs in patients with acute myocardial infarction seems to be lowered in the morning hours and significantly better in late daytime (Reisin et al. 2004). Knowledge of the risks of circadian thrombosis was updated by the discovery of the higher frequency of the onset of symptomatic subacute stent thrombosis after bare metal coronary stent implantation (Tamura et al. 2006). As very little was still known about the efficacy of circadian thrombolysis and the elevation of some characteristics in myocardial infarction, De Luca and co-workers (2005) analysed data on 1548 patients with ST-segment elevation myocardial infarction treated by primary angioplasty. Patients treated between 1 p.m. and midnight had a lower prevalence of anterior infarction and longer door-to-ballon time, whereas patients treated between 8 a.m. and 4 p.m. had the best myocardial perfusion and lowest a 1-year mortality rate.

Chronotoxicity for marrow cells has been shown in several new xenobiotics, among other irinotecan (Filipski et al. 2004b) and nedaplatin (Cui et al. 2004).

\section{SEASONAL CHANGES}

Circannual variations have been documented for the blood and haematopoietic system of many wild species as well as for laboratory animals under artificial controlled conditions (Berger 1983). Recently, seasonal changes were documented for the haemocyte counts of the Austropotamus torrentinum (Lucic and Erben 2005), baseline levels of DNA migration and micronucleus frequency in Dreissena polymorpha (Bolognesi et al. 2004), haemocyte counts and size in the Manila clam Venerupis philippinarum (Soudant et al. 2004), the innate immunity of the Asian catfish Clarias batrachus (Kumari et al. 2006) and the haematocrit and total leucocyte counts in the wild roach Rutilus rutilus (Vainikka et al. 2004).

Increased platelet activation was observed in patients with chronic allergic asthma. KasperslaZajac and Rogala (2006) reported an increase in the plasma level of platelet factor 4 in patients with seasonal allergic rhinitis and concomitant asthma was revealed by.

Two significant nadirs of bone marrow engraftability in mice were documented at 8 and 24 hours after the onset of light, ie. in the subjective morning and noon, in July, while in February, nadirs were showing only in the subjective morning (D'Hondt et al. 2004).

\section{CIRCADIAN CLOCK}

We know very little about the role of clock genes in haematopoietic and blood cells. We can speculate that these peripheral clock genes (i) generate rhythm in their own cells independently of the clock genes in the hypothalamus, or (ii) only modify central clock gene regulation, or (iii) 
modify another dominant clock. The fact that leukocytes produce melatonin (Hardeland et al. 2006) can offer the possibility of the autonomy of this peripheral clock.

Expression of clock gene hPer1 in human peripheral mononuclear cells has been detected .(Burioka et al. 2005); the glucocorticoid homologue dexamethasone rapidly affected the expression of hPer1 mRNA in these cells in vitro, suggesting that human circulating mononuclear cells may be a useful surrogate marker for the investigation of drug effects on clock genes. Although the collection of rare haematopoietic stem cells without reduced RNA quality is difficult, high-speed flow cytometric sorting and Q-RT-PCR makes available (Tsinkalovsky et al. 2005) to measure levels of mRNA of major clock genes mPer1, mPer2, mBmal1, mCry1, mClock and mRev-erb.

Some proapoptotic drugs have displayed lowest toxicity and greatest antitumour efficacy when administered during the circadian rest phase. For example, in mouse mammary adenocarcinoma cells, the proportion of G2/M-phase increases from late rest to late activity span and no circadian rhythm was found in BCL-2. This means the circadian organisation in cell-cycle phase distribution is shifted and BCL-2 rhythm ablated while in bone marrow, which is likely to be a circadian clock regulated bcl-2 and bax expression, increasing cellular protection against programmed cell death during the rest span (Granda et al. 2004).

Although the relationship between clock genes in suprachiasmatic nucleus and melatonin synthesis is known (cf. Richter et al. 2004) as well as the hypothesis concerning melatonin induction of rhythms in the bone marrow (Maestroni 1998), any direct experimental evidence confirming that suprachiasmatic clock genes generate haematologic rhythms has not been found to date. Thus, the existence of an autonomous clock for haematoimmune system cannot be disclaimed (Berger 2004b). Recent observations on mice with destroyed suprachiasmatic nuclei showed that their marrow cell cycle phase distribution was not altered (Filipski et al. 2004a). This could be further evidence that the haemato-immune system has its own circadian clock.

\section{ACKNOWLEDGEMENTS}

This work was partially supported by grant no $1274 / 06$ from the Ministry of Education of the Czech Republic.

\section{REFERENCES}

Aldemir H., Kilic N.: The effect of time of day and exercise on platelet functions and plateletneutrophil aggregates in healthy male subjects. Mol. Cell. Bioch. 280:119-124, 2005.

Barkova E.N., Nazarenko E.V.: Circadian dynamics of monocyte phagocytic activity in women during lactation complicated by iron deficiency. Bull. Exper. Biol. Med. 140:29-32, 2005.

Berger J.: Seasonal influences on circadian rhythms in the blood picture of SPF rats housed under artificial illumination. Folia haematol. 110:55$70,1983$.

Berger J.: Regulation of circadian rhythms. J. Appl. Biomed. 2:131-140, 2004a.

Berger J.: Chronohaematology. J. Appl. Biomed. 2:179-185, 2004b.

Bolognesi C., Buschini A., Branchi E. et al.: Comet and micronucleus assays in zebra mussel cells for genotoxicity assessment of surface drinking water treated with three different disinfectants. Sci. Total Environm. 333:127-136, 2004.

Burioka N., Takata M., Okano Y. et al. : Dexamethasone influences human clock gene expression in bronchial epithelium and peripheral blood mononuclear cells in vitro. Chronobiol. Intern. 22:585-590, 2005.

Cui Y., Sugimoto K.-I., Kawai Y. et al.: Chronotoxicity of nedaplatin in rats. Chrobiol. Int. 21:601-611, 2004.

Dubochovich M.L., Markowska M. : Functional MT1 and MT2 melatonin receptors in mammals. Endocrine 27:101-110, 2005.

Filipski E., King V.M., Etienne M.-C. et al.: Persistent twenty-four hour changes in liver and bone marrow sepite suprachiasmatic nuclei ablation in mice. Amer. J. Physiol. - Regulat. Integr. Comp. Physiol. 287:R844-R851, 2004a.

Filipski E., Lemaigre G., Liu X.-H. et al.: Circadian rhythm of irinotecan tolerability in mice. Chronobiol. Int. 21:613-630, 2004b.

Granda T.G., Liu X.-H., Smaaland R. et al.: Circadian regulation of cell cycle and apoptosis proteins in mouse bone marrow and tumor. FASEB J. 19:304-306, 2005.

Hardelanf R, Pandi-Perumal S.R., Cardinali D.P.: Melatonin. Int. J. Biochem. Cell Physiol. 38:313-316, 2006.

D'Hondt L., McAuliffe C., Damon J. et al.: Circadian variation of bone marrow engraftability. J. Cell. Physiol. 200:63-70, 2004.

Hriscu M.L.: Modulatory factors of circadian phagocytic activity. Ann. N.Y. Acad. Sci. 1057:403-430, 2005.

Kasperska-Zajac A., Rogala B.: Behaviour of indexes of platelet activity and active fibrinolysis in plasma from patients with seasonal allergic rhinitis and concomitant 
asthma during pollen seasin. Adv. Clin. Exper. Med. 15:23-28, 2006.

Kudo T., Nakayama E., Suzuki S. et al.: Cholesterol diet enhances daily rhythm of PAI-1 mRNA in the mouse liver. Amer. J. Physiol. - Endocrinol. Metab. 287:E644-E651, 2004.

Kumari J., Sahoo P.K., Swain T. et al.: Seasobal variation in the innate immune parametrs of the Asian catfish Clarias batrachus. Aquaculture 252:121-127, 2006.

Kwiatkowski F., Lévi F.: Chronobiologie et immunité. Pathol. Biol. 53:251-254, 2005.

Maestroni G.J.M.: Is hematopoiesis under the influence of neural and neuroendocrine mechanisms? Histol. Histopathol. 13:271-273, 1998.

Oishi K., Ohkura N., Kasamatsu M. et al.: Tissuespecific augmentation of circadian PAI-1 expression in mice with streptozotocin-induced diabetes. Thromb. Res. 114:129-135, 2004.

Osmancik P., Kvasnicka J., Widimski P., Tarnok A.: Diurnal variation of soluble E- and Pselectin, and intercellular adhesion molecule-1 in patients with and without coronary artery disease. Cardiology 102:194-199, 2004.

Piccione G., Fazio F., Giudice E. et al.: Nycthemeral change of some haematological parameters in horses. J. Appl. Biomed. 3:123128, 2005a.

Piccione G., Percipalle M., Fazio F. et al.: Circadian variation of blood clotting time and circulating vitamin $\mathrm{K}$ in the athletic horse. Com. Clin. Pathol. 14:86-89, 2005b.

Reisin L.H., Pancheva N., Berman M. et al.: Circadian variation of the efficacy of thrombolytic therapy in acute myocardial infarction - isn't the time ripe for cardiovascular chronotherapy? Angiology 55:257-263, 2004.

Reppert S.M., Weaver D.R.: Molecular analysis of mammalian circadian rhythms. Ann. Rev. Physiol. 63:647-676, 2001.
Roberts, J.E.: Update on the positive effects of light in humans. Photochem. Photobiol. 81:490-492, 2005.

Richter H.G., Torres-Farfń C., Rojas-García P.P. et al.: The circadian timing system: making sense of day/night gene expression. Biol. Res. 37:1128. 2004.

Sánchez S., Paredes S.D., Martín M.I. et al: Effect of tryptophan administration on circulating levels of melatonin and phagocytic activity. J. Appl. Biomed. 2:169-177, 2004.

Soudant P., Paillard C., Choquet G. et al.: Impact of season and rearing site on the physiological and immunological parameters of the Manila clam Venerupis $(=$ Tapes, $=$ Ruditapes) philippinarum. Aquaculture 229:401-418, 2004.

Tamura A., Watanabe T., Nagase K. et al.: Circadian variation in symptomatic subacute stent thrombosis after bare metal coronary stent implantation. Amer. J. Cardiol. 97:195-197, 2006.

Tsinkalovsky O., Rosenlund B., Laerum O.D., Eiken H.G.: Clock gene expression in purified mouse hematopoietic stem cells. Exper. Hematol. 33:100-107, 2005.

Vainikka A., Jokinen E.T., Kortet R., Taskinen J.: Gender- and season-dependent relationships between testosterone, oestradiol and immune functions in wild roach. J. Fish Biol. 64:227240, 2004.

Wolach B., Ashkenazi M., Grossmann R. et al.: Diurnal fluctuation of leukocyte G6PD activity. A possible explanation for the normal neutrophil bactericidal activity and the low incidence of pyogenic infections in patients with severe G6PD deficiency in Israel. Pediatr. Res. 55:807-813, 2004. 